\title{
Marc Bergère, Vichy au Canada. L'exil québécois de collaborateurs français. Rennes : PUR, 2015, 328 p., ISBN 978-2-7535-4173-3.
}

Jean-Marc Berlière

\section{(2) OpenEdition \\ Journals}

Édition électronique

URL : http://journals.openedition.org/chs/1685

DOI : $10.4000 /$ chs. 1685

ISSN : 1663-4837

Éditeur

Librairie Droz

Édition imprimée

Date de publication : 1 décembre 2016

Pagination : 328

ISBN : 978-2-600-01953-8

ISSN : 1422-0857

Référence électronique

Jean-Marc Berlière, "Marc Bergère, Vichy au Canada. L'exil québécois de collaborateurs français.

Rennes : PUR, 2015, 328 p., ISBN 978-2-7535-4173-3. », Crime, Histoire \& Sociétés / Crime, History \&

Societies [En ligne], Vol. 20, n² | 2016, mis en ligne le 01 décembre 2018, consulté le 24 septembre 2020. URL : http://journals.openedition.org/chs/1685; DOI : https://doi.org/10.4000/chs. 1685

Ce document a été généré automatiquement le 24 septembre 2020.

(C) Droz 


\title{
Marc Bergère, Vichy au Canada. L'exil québécois de collaborateurs français. Rennes : PUR, 2015, 328 p., ISBN 978-2-7535-4173-3.
}

\author{
Jean-Marc Berlière
}

1 On connaissait relativement bien les exils - sud-américain, scandinave, suisse, et surtout espagnol - d'un certain nombre de responsables politiques, écrivains, journalistes, miliciens... engagés dans une collaboration plus ou moins active avec l'occupant qui, peu soucieux d'affronter les foudres d'une justice sous influence et les débordements d'une épuration sanglante, ont choisi l'exil pour mettre quelque distance et quelques frontières entre eux et l'article $75 \mathrm{du}$ Code pénal.

On connaissait très peu, en revanche, l'exil de quelques figures de la collaboration au Québec, province du Canada lié au camp allié, ce qui n'allait pas sans poser de multiples problèmes aux autorités politiques et religieuses de la Belle Province dont le catholicisme et certaines analyses communes lui avaient fait considérer le régime, l'idéologie, la "Révolution nationale » du maréchal Pétain avec une sympathie qui a permis de parler d'un " pétainisme sans l'Occupation » (Marc Ferro) ou mieux encore d'un « pétainisme sans collaboration »'.

3 Le premier mérite de cet ouvrage, que Marc Bergère a tiré de son mémoire d'HDR ${ }^{2}$, est donc de nous plonger dans une période de l'histoire du Québec mise au jour depuis les années 1990 par l'historiographie - le rêve d'un "Vichy sur Saint Laurent " ${ }^{3}-$ et de le faire par ce biais en abordant de plain-pied les difficultés - diplomatiques, politiques, morales... - posés par ce choix logique d'une poignée de miliciens. Comme le rappelle Marc Bergère «moins que leur importance numérique [...] c'est l'écho significatif de leur présence et les soutiens non négligeables dont ils ont pu bénéficier au sein de la société québécoise » qui furent à l'origine d'une «mobilisation politique et sociale qui s'apparente de fait à une véritable 'affaire d'état'». Cette affaire d'état, l'auteur la restitue avec précision à partir de sources québécoises variées, précises et souvent 
passionnantes. Il en montre également les limites: celles d'un épiphénomène circonscrit à certains groupes politiques et religieux activistes. Le rappel de cette hésitation entre Vichy et la France libre qui ne caractérise pas le seul Canada, s'inscrit par ailleurs dans un mouvement historiographique qui s'intéresse depuis une bonne dizaine d'années à Vichy « hors les murs ", notamment à l'étude des relations et relais diplomatiques d'un régime qui incarnait et représentait le pouvoir légal et reconnu de la France, ou encore à l'enracinement - très divers - de l'idéologie pétainiste dans l'empire ${ }^{4}$.

4 Un autre intérêt de ce travail est de s'attacher, parmi les miliciens ayant choisi l'exil québécois, à la figure de Jacques Dugé de Bernonville qui cristallisa toutes les passions soulevées par Vichy, la collaboration, l'épuration ${ }^{5}$. Le chapitre consacré à cet activiste d'extrême droite, monarchiste, catholique fervent, ce vrai faux aristocrate, engagé volontaire en 1916 dans les chasseurs alpins, décoré de la Légion d'honneur à titre militaire - comme Darnand ou Bucard - militant d'Action française, camelot du Roy, qui fut de tous les complots d'extrême droite (UCAD, OSARN...) avant-guerre est passionnant. Adhérant d'enthousiasme à la Révolution nationale, Bernonville va, comme beaucoup d'autres "nationaux " oublier son patriotisme et, au service du nouveau régime, collaborer avec le vainqueur et l'occupant. On le retrouve ainsi dans pratiquement toutes les officines policières ou militaires, parallèles, officielles ou officieuses, nées de la situation si particulière de l'Occupation: les Groupes de protection du colonel Groussard, le Service d'ordre légionnaire de Darnand, le Commissariat général aux questions juives, «l'équipe », police occulte initiée par le docteur Ménétrel, mais manipulée par l'Abwehr, la Milice française, la Waffen-SS, le Corps des volontaires français (CVF) ${ }^{6}$, etc...

5 Homme des missions occultes, cet ultra de la collaboration va plonger au coeur de la guerre civile qui peu à peu s'installe en France : on le retrouve chef milicien à Glières, dans le Vercors, puis à la tête du Maintien de l'ordre en Bourgogne puis à Lyon. Parti en Allemagne, parachuté en France, il disparaît, sans doute protégé et caché dans des établissements religieux avant de réapparaître au Québec.

On comprend pourquoi le séjour entre 1946 et $1951^{7}$ d'un tel personnage, il arrive au Québec déguisé en ecclésiastique, ait pu susciter polémiques et passions.

\section{NOTES}

1. Éric Amyot, Le Québec entre Pétain et De Gaulle, Montréal, Fides, 1999.

2. La Postérité de Vichy au Québec. L'affaire des "réfugiés politiques" français après 1945 : retour sur l'événement, sa mémoire et l'écriture de son histoire (Paris I, 2003).

3. Esther Delisle, Mythes, mémoire et mensonges : l'intelligentsia du Québec devant la tentation fasciste, 1939-1960. Montréal, Robert Davies, 1998.

4. Sur ce « Vichy colonial », Cf. Jacques Cantier, L’Algérie sous le régime de Vichy, Odile Jacob, 2002 ; Eric Jennings, Vichy sous les tropiques. La Révolution nationale à Madagascar, en Guadeloupe et en 
Indochine. Grasset, 2004 ; Vincent Joly, Le Soudan français de 1939 à 1945. Karthala, 2006 ; Jacques Cantier, Eric Jennings (dir.), L'Empire colonial sous Vichy, Odile Jacob, 2004.

5. Yves Lavertu, L'Affaire Bernonville. Le Québec face à Pétain et à la collaboration. Montréal, VLB, 1994.

6. Les passages concernant l'école de Taverny et le CVF montrent quelque confusion entre ce CVF et le Selbstschutz mis en place à l'instigation d'Oberg.

7. Qu'il quittera pour le Brésil où il est mort en 1972. 